\title{
EFFECT OF SILICA ON ALKALINE BAGASSE CELLULOSE AND SOFTWOOD CELLULOSE
}

\author{
Samson Masulubanye Mohomane ${ }^{1}$, Setumo Victor Motloung ${ }^{2,3}$, Lehlohonolo \\ Fortune Koao ${ }^{4}$, Tshwafo Elias Motaung ${ }^{3,5}$ \\ 1University of Zululand, South Africa \\ 2 Nelson Mandela University, South Africa \\ ${ }^{3}$ Sefako Makgatho Health Sciences University, South Africa \\ ${ }^{4}$ University of The Free State, South Africa \\ 5 University of South Africa, South Africa
}

\begin{abstract}
This study investigates the effect of silica on sugarcane bagasse (SCB) and softwood (SW) cellulose. Cellulose was extracted from raw SCB and SW chips using a three-step process, namely thermal pre-treatment, alkaline treatment and bleaching treatment. Alkali treated cellulose was then subjected to silica surface modification using the solvent exchange method. The effect of silica modification on SCB and SW cellulos was investigated using X-ray diffractions analysis (XRD), Fourier transform infrared (FTIR) spectroscopy and optical microscope (OPM) techniques. Both the FTIR and XRD results confirm successful extraction of cellulose from both raw fibers and addition of silane functional groups in the cellulose surface. XRD patterns of all samples revealed typical spectra for natural fibers corresponding to crystalline peaks of cellulose and undissolved amorphous hemicellulose respectively. SCB and SW showed similar increasing patterns of crystallinity with nanosilica surface modification. The surface morphology results showed that both SCB and SW cellulose modified with silica were swollen and displayed small particles agglomerating on the surface of the fibers. The solvent exchange method proved to be a successful method for modifying SCB and SW cellulose with nanosilica. It also proved to be cost-efficient and time-efficient.
\end{abstract}

KEYWORDS: Sugarcane bagasse, soft wood, cellulose, silica.

\section{INTRODUCTION}

There is a significant research interest in the application of natural fibers in the field of polymer composites due to their many advantages. Natural fibers are abundant, renewable, non-abrasive, non-toxic and biodegradable as compared to synthetic fibers. They also possess 
outstanding mechanical properties with varying morphology and good surface properties (Sequeira et al. 2009, Jacob et al. 2005, Eichhorn et al. 2001, Sibuya et al. 2018). Amongst the natural fibers, sugarcane bagasse $(\mathrm{SCB})$ is one of the major agricultural residues that have gained popularity lately and an exceptional fiber for composites reinforcement because of low modification cost and high quality composites attained. SCB is a versatile fibrous agricultural residue that is obtained after extraction of 'juice' from sugarcane, that can be can be converted to paper, feedstock, biofuel amongst others. It can also be used as an absolute substrate for microbial processes to produce electricity, chemicals, enzymes, and other valuable products. SCB contains about $40-50 \%$ cellulose, $25-30 \%$ of hemicellulose and about $20-25 \%$ of lignin content. It has been used for reinforcement for thermoplastics in the automotive, construction and food packaging industries (Loh et al. 2013, Mulinari et al. 2009, Ahmed et al. 2012).

Soft wood (SW) is one of the most used natural fibers in thermoplastic reinforcement. The main components in SW are cellulose, lignin and hemicellulose which account for 55\%, 11\% and $26 \%$ respectively. Wood elements employed in polymer composites vary in shape and can be used in combinations or alone. The shape and wood fiber size determine the properties of the final product such as surface chemistry. The strength of wood polymer composites depends on factors like chemical compositions, density, thickness, fiber content, and the type of bonding agent (if any). Softwood has applications in architectural woodwork, composite materials, construction and furniture fields (Terrett et al. 2019, Ashori, 2008). Cellulose is one of the highly abundant natural polymers found in earth. It can be extracted from several sources including bagasse, wood, cotton, pineapple leaves and sisal fibers amongst others. Structurally, it consist of D-anhydroglucopyranose units which are joined to form a linear molecular chain. Cellulose extraction is normally a three-step process, i.e. thermal pre-treatment, alkaline treatment and bleaching treatment. The alkalization step removes non-cellulosic components such as lignin, hemicellulose, waxes and pectin. The treatment increases the roughness of the fiber surface resulting in the improved adhesion between the fibre and the matrix (Zhao et al. 2013, Barra et al. 2006, Linganiso et al. 2019).

Silica $\left(\mathrm{SiO}_{2}\right)$ is mainly found as quartz in nature and in various living organisms. Silica as a filler is known for enhancing mechanical strength, thermal stability and transparency. It makes cellulose composites hydrophobic and resistant to structural deformation (Litschauer et al. 2011, Ha et al. 2019). Cellulose modification results in morphology changes and increases in hydroxyl groups. Hence, cellulose surface modification enhance surface tension, wettability, swelling, adhesion and compatibility with polymers (Ashori et al. 2008, Wei et al. 2015). The preparation of cellulose-silica composites can be achieved in various ways such as acid-catalyzed hydrolysis, sol-gel method or using precursors like tetraethoxysilane (TEOS) (Cerchiara et al. 2018, Maleki et al. 2014) amongst others. One of the cheap and simple methods of preparing cellulose-silica composites is the solvent exchange method, which substituted the need for surfactants when incorporating cellulose fibers into non-polar polymers. This method uses the percolating approach to prepare the cellulose surface for effective facial interaction with hydrophobic silica and allow the incorporation of composite formation without the use of catalysts and crosslinking agents. The cellulose fiber assembles to a three-dimensional template, then the percolating structure is then filled with nanosilica. Cellulose-silica composite normally takes days and energy to synthesize it. However, it only takes a few hours using the solvent exchange method because it is a one-step energy-efficient method. This method yields a composite with reduced moisture absorption, enhanced thermal properties and dimensionally stability (RodríguezRobledo et al. 2018). In a study by Barra et al. (2006), the treatment of sisal fiber with silica showed improvement in tensile strength, impact strength and tensile modulus. There are also changes in morphology and porosity of the cellulose-silica composite depending on the silica 
content. Silica-based composites can be used to coat implants and medical products as biosensors, biocatalysts, and matrix for a controlled release of drugs (Hou et al. 2010, Xie et al. 2009). Due to their antifungal activity property, such composites can be used to avoid the growth of Aspergillus Versicolor which degrades paper artwork such as books, manuscripts, paintings, etc. (RodríguezRobledo et al. 2018, Cerchiara et al. 2018).

\section{MATERIALS AND METHODS}

Sugarcane bagasse was obtained from Tongaat Hullets sugar mill in Felixton, South Africa. Softwood (Pinus patula) chips was obtained from the nearby farm in Empangeni, South Africa. Silica $\left(\mathrm{SiO}_{2}\right)$, sodium hydroxide $(\mathrm{NaOH})$, sodium chlorite $\left(\mathrm{NaCIO}_{2}\right)$, glacial acetic acid $\left(\mathrm{CH}_{3} \mathrm{COOH}\right)$, acetone $\left(\mathrm{C}_{3} \mathrm{H}_{6} \mathrm{O}\right)$, and ethanol $\left(\mathrm{CH}_{3} \mathrm{COOH}\right)$ were purchased from Laboratory consumables, South Africa. All chemicals were used without further purification.

\section{Thermal pre-treatment}

SCB and SW feedstock were separately subjected to thermal pre-treatment. The feedstock was boiled with water for an hour on a hot plate. The mixture was removed from the hot plate and rinsed with distilled water. The process was repeated four times to ensure that impurities and any dirt trapped were effectively removed.

\section{Alkaline treatment}

The thermally pre-treated SCB and SW were treated with an alkaline solution $(2 \% \mathrm{NaOH})$ prepared by dissolving $100 \mathrm{~g} \mathrm{NaOH}$ in 5L distilled water. The mixture was boiled for an hour and rinsed with distilled water. The process was repeated four times.

\section{Bleaching}

The buffer solution was prepared by adding $54 \mathrm{~g} \mathrm{NaOH}, 150 \mathrm{~mL}$ acetic acid, and distilled water in $2 \mathrm{~L}$ volumetric flask. The solution of sodium chlorite (3.5\%) was prepared by dissolving $70 \mathrm{~g} \mathrm{NaIO}_{4}$ salt in $2 \mathrm{~L}$ distilled water. The buffer and sodium chlorite solution were mixed in 1:1 volume ratio before used. Alkali pre-treated fibers were boiled the solution for an hour before rinsed with distilled water. The same process was repeated four times.

\section{Solvent exchange method}

Firstly, water was added in droplets into cellulose fibers while stirring for $15 \mathrm{~min}$ to form a gel. The gel mixture was added to ethanol in 1:1 volume ratio and stirred for about an hour before acetone was added drop wise in a 1:2 volume acetone-water ratio. Stirring was continued for 3 hours more before nanosilica which was previously immersed in acetone was added. The mixture was further stirred for $10 \mathrm{~min}$. Lastly, the mixture was sonicated for $20 \mathrm{~min}$ at an ultrasound bath of $40 \mathrm{kHz}$, maintaining the temperature below $40^{\circ} \mathrm{C}$ before the resultant product was dried at $60^{\circ} \mathrm{C}$ in an oven.

\section{Characterization techniques} Optical microscope (OPM)

The powdered samples of cellulose and its silica composites were analysed using the Zeiss optical microscope. The morphology was captured using a digital system. A small amount of each sample was spread on a glass slide and stamped with a coverslip. 
$X$-Ray diffraction analysis (XRD)

The samples were analysed using X-ray diffractometer (D8-Advance Bruker AXS GmbH) at room temperature $(\mathrm{RT})$ with a monochromatic $\mathrm{CuK} \alpha$ radiation source $(\lambda=0.1539 \mathrm{~nm})$ in the step-scan mode with a $2 \theta$ angle ranging from $0^{\circ}$ to $60^{\circ}$ with a step of 0.04 and scanning time of $5.0 \mathrm{~min}$.

\section{Fourier transform infrared (FTIR) spectroscopy}

The spectra of all samples were carried out on a Perkin-Elmer FTIR spectrophotometer using a standard ATR cell. The gauge was adjusted to 90 for sufficient contact. All samples were scanned over the wavenumber $\left(450-4000 \mathrm{~cm}^{-1}\right)$.

\section{RESULTS AND DISCUSSION}

\section{Spectral analysis}

The FTIR spectra of SCB and SW celluloses as prepared are shown in Fig. 1. Both spectra showed the common peaks associated with cellulosic materials at $3336 \mathrm{~cm}^{-1}(\mathrm{OH}-\mathrm{stretch})$, $2890 \mathrm{~cm}^{-1}$ (C-H asymmetric stretch), $1560 \mathrm{~cm}^{-1}(\mathrm{C}=\mathrm{C})$ aromatic asymmetric stretch), $1031 \mathrm{~cm}^{-1}$ (C-O vibrations), and $560 \mathrm{~cm}^{-1}$ (C-OH out of plane) as reported in the literature (Maeda et al. 2006, Rodríguez-Robledo et al. 2018).

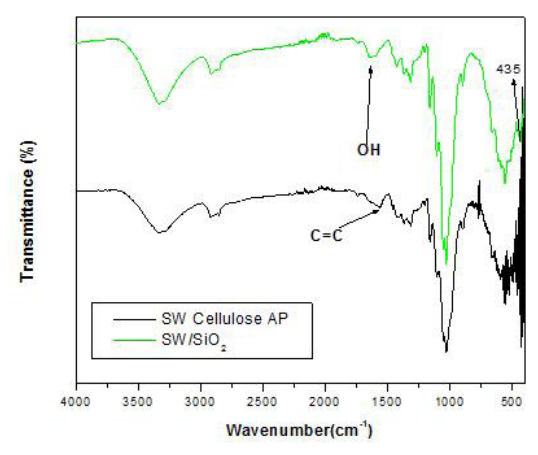

a)

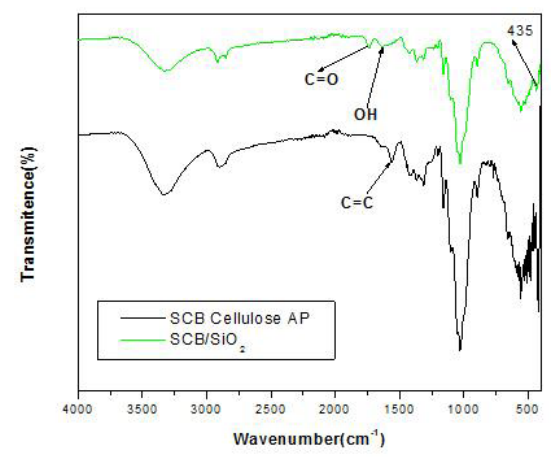

b)

Fig. 1: The FTIR spectra of a) $S W$ cellulose and $S W / S i O_{2}$ b) $S C B$ cellulose and $S C B / S i O_{2}$.

Moreover, the peaks linked to aromatic skeletal vibrations of lignin and hemicelluloses at $1241 \mathrm{~cm}^{-1}$ and $1722 \mathrm{~cm}^{-1}$ were reduced and are almost invisible. This might indicates the complete removal of lignin and hemicelluloses from SCB and SW. With the introduction of nanosilica in both SCB and SW celluloses, there are evident shifts in peak positions and intensities. The peaks at around $1315 \mathrm{~cm}^{-1}$ only appear in the prepared SCB and SW celluloses spectra corresponding with $\mathrm{CH} 2$ vibration functional groups (Jacob et al. 2005). The peak at $1367 \mathrm{~cm}^{-1}$ only appear in the modified SCB and SCW cellulose spectra. This peak correspond with $\mathrm{C}-\mathrm{H}$ bending in the plane (Sibiya et al. 2018, Zhao et al. 2013, Linganiso et al. 2019) and could symbolise introduction of a new functional group resulting from silica modification. In addition, the peak at $435 \mathrm{~cm}^{-1}$ attributed to $\mathrm{Si}-\mathrm{O}-\mathrm{Si}$ bending only appears in modified cellulose which is evidence that nanosilica functional groups were added on the cellulose surface (Rodríguez-Robledo et al. 
2018, Cerchiara et al. 2018, Maleki et al. 2014). The -OH from silanol absorbs around $1030 \mathrm{~cm}^{-1}$ and $3300 \mathrm{~cm}^{-1}$ might be the reason for bigger intensities observed in modified cellulose. These peaks are more pronounced in SW cellulose as compared to SCB cellulose. This may be due to the reduction in hydrogen bonding in cellulosic $\mathrm{O}-\mathrm{H}$ groups, thereby increasing $-\mathrm{OH}$ concentration due to high energy of $\mathrm{O}-\mathrm{H}$ bonds

\section{$\mathrm{X}$-Ray diffraction analysis}

Fig. 2 is showing the diffractograms of SCB and SW celluloses as prepared and modified respectively. Both prepared and modified fibers display typical spectra for natural fibers with peaks around $16^{\circ}, 23^{\circ}$, and $35^{\circ}$ corresponding to amorphous cellulose I, crystalline cellulose II and undissolved amorphous hemicellulose respectively (Pothan et al. 2002, Xie et al. 2009). With the introduction of silica to SCB cellulose, there were minor changes in peaks positions observed and an increase in peak intensities. The minor peaks shift for SCB may be due to disorder caused by modification of fiber and might indicate an increase in the interplanar distance. The intensity increase could suggest that the nanosilica modification improved the crystallinity of SCB. The same trend was observed with SW cellulose.
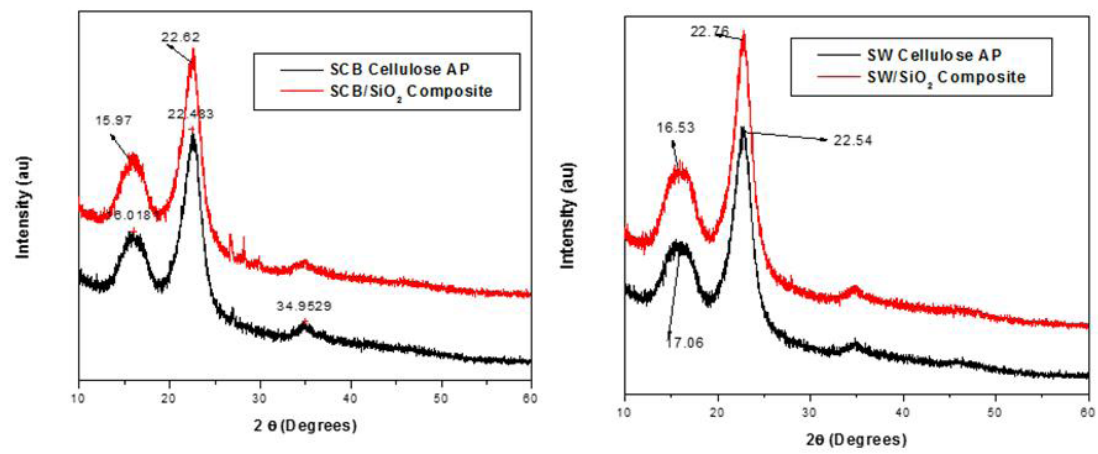

Fig. 2. The diffractograms of $\mathrm{SCB}$ cellulose, $\mathrm{SCB} / \mathrm{SiO}_{2}, \mathrm{SW}$ cellulose and $\mathrm{SW} / \mathrm{SiO}_{2}$.

Tab. 1: The crystalline indices and degree of crystallinity for unmodified and modified (SCB and SW) cellulose.

\begin{tabular}{|l|c|c|}
\hline \multicolumn{1}{|c|}{ Sample } & Peak height CI (\%) & Deconvolution Cl (\%) \\
\hline $\mathrm{SW}$ cellulose AP & 42 & 63 \\
\hline $\mathrm{SW} / \mathrm{SiO}_{2}$ & 43 & 64 \\
\hline $\mathrm{SCB}$ cellulose AP & 39 & 62 \\
\hline $\mathrm{SCB} / \mathrm{SiO}_{2}$ & 40 & 63 \\
\hline
\end{tabular}

Tab. 1 showed the crystallinity index (CI) estimated using the deconvolution and peak height methods (Ciolacu et al. 2011, Johar et al. 2012, Kim et al. 2013). For both SCB and SW cellulose, there was an increase in crystallinity with the introduction of silica as expected. The differences in crystallinity index values for both SCB and SW might be due to differences in chemical compositions and exposure of cellulose after alkali treatment. It is clearly evident that the addition of nanosilica particles improves the crystallinity of both SCB and SW cellulose. 


\section{Optical microscope}

The optical microscope images of unmodified and modified SCB and SW cellulose are displayed in Fig. 3. It could be seen that both SCB and SW unmodified fibers are thin and longer as compared with their modified counterparts. Both $\mathrm{SCB} / \mathrm{SiO}_{2}$ and $\mathrm{SW} / \mathrm{SiO}_{2}$ are swollen and display dusty small particles agglomerating on the surface of the fibers (see arrows). Similar results were also reported in modification of natural fibres (Mulinari et al. 2009, Maeda et al. 2006).
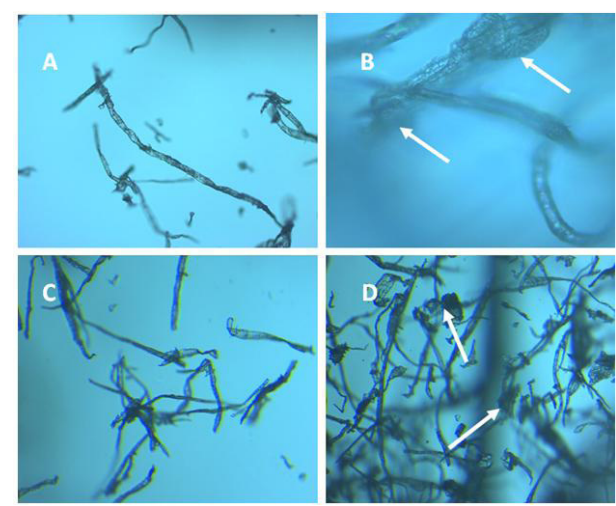

Fig. 3: The optical microscope images of: a) SCB Cellulose, b) $\mathrm{SCB} / \mathrm{SiO}_{2}$, c) SW Cellulose and d) SW/ $\mathrm{SiO}_{2}$ at $10 \times 0.22$ magnification.

According to Pothan et al. (2002), the swelling of the fiber leads to a transfer of the electrochemical double layer and the shear plane of the fiber to the electrolyte solution. Moreover, the fiber length for both SCB and SW were not affected by modification. In fact, the longer fibers $(5 \mathrm{~mm})$ have a property to allow high stress to be transferred to reinforcement and that contributes to its superior mechanical properties (Loh et al. 2013).

\section{CONCLUSIONS}

The study investigated the effect of silica on sugarcane bagasse (SCB) and softwood (SW) cellulose properties. FTIR and XRD results confirmed that cellulose was successfully extracted from SCB and SW using the alkali treatment. The surface modification of both SCB and SW cellulose were performed successfully using the solvent exchange method. FTIR analysis confirmed that silica functional groups were successfully added onto the surface of SCB and SW cellulose. There were evident shifts in peak positions and intensities with the introduction of silica. New peaks were detected at $1367 \mathrm{~cm}^{-1}$ and $435 \mathrm{~cm}^{-1}$ signaling that nanosilica functional groups were added on the cellulose surface. XRD patterns showed minor changes in peaks positions and an increase in peak intensities with the introduction of silica. There was also an increase in crystallinity index estimated using the deconvolution and peak-height method for both modified SW and SCB cellulose. The surface morphology displayed fiber swelling with introduction of silica, which has impact on mechanical properties of the fiber and the resultant composites. The solvent method proved to be cheap, simple and time efficient for use in cellulose modification. 


\section{REFERENCES}

1. Ahmed, I.I., Gupta, A.K., 2012: Sugarcane bagasse gasification: Global reaction mechanism of syngas evolution. Applied Energy 91(1): 75-81.

2. Ashori, A., 2008: Wood-plastic composites as promising green-composites for automotive industries! Bioresource technology 99(11): 4661-4667.

3. Barra, G.M., Fredel, M.C., Qureshi, H.A., Taylor, A.W., Clemenceau, Jr.C., 2006: Properties of chemically treated natural amorphous silica fibers as polyurethane reinforcement. Polymer Composites 27(5): 582-590.

4. Cerchiara, T., Palermo, A.M., Esposito, G., Chidichimo, G., 2018: Effects of microwave heating for the conservation of paper artworks contaminated with Aspergillus versicolor. Cellulose 25(3): 2063-2074.

5. Ciolacu, D., Ciolacu, F., Popa, V.I., 2011: Amorphous cellulose-structure and characterization. Cellulose chemistry and technology 45(1): 13.

6. Demilecamps, A., Beauger, C., Hildenbrand, C., Rigacci, A., Budtova, T., 2015: Cellulosesilica aerogels. Carbohydrate Polymers 122: 293-300.

7. Eichhorn, S.J., Baillie, C.A., Zafeiropoulos, N., Mwaikambo, L.Y., Ansell, M.P., Dufresne, A., Entwistle, K.M., Herrera-Franco, P.J., Escamilla, G.C., Groom, L., Hughes, M., 2001: Current international research into cellulosic fibres and composites. Journal of materials Science 36(9): 2107-2131.

8. Ha, S.W., Weiss, D., Weitzmann, M.N., Beck Jr. G.R., 2019: Applications of silica-based nanomaterials in dental and skeletal biology. Nanobiomaterials in Clinical Dentistry Pp 77-112.

9. Hou, A., Yu, Y. and Chen, H., 2010: Uniform dispersion of silica nanoparticles on dyed cellulose surface by sol-gel method. Carbohydrate Polymers 79(3): 578-583.

10. Jacob, M., Joseph, S., Pothan, L.A., Thomas, S., 2005: A study of advances in characterization of interfaces and fiber surfaces in lignocellulosic fiber-reinforced composites. Composite Interfaces 12(1-2): 95-124.

11. Johar, N., Ahmad, I., Dufresne, A., 2012: Extraction, preparation and characterization of cellulose fibres and nanocrystals from rice husk. Industrial Crops and Products 37(1): 93-99.

12. Kim, S.H., Lee, C.M., Kafle, K., 2013: Characterization of crystalline cellulose in biomass: basic principles, applications, and limitations of XRD, NMR, IR, Raman, and SFG. Korean Journal of Chemical Engineering 30(12): 2127-2141.

13. Linganiso L.Z., Buthelezi T., Motaung T.E., 2019: A comparative study of sugarcane bagasse and soft wood. Wood Research 64: 273-280.

14. Litschauer, M., Neouze, M.A., Haimer, E., Henniges, U., Potthast, A., Rosenau, T., Liebner, F., 2011: Silica modified cellulosic aerogels. Cellulose 18(1): 143-149.

15. Loh, Y.R., Sujan, D., Rahman, M.E., Das, C.A., 2013: Sugarcane bagasse. The future composite material: A literature review. Resources, Conservation and Recycling 75: 14-22.

16. Maeda, H., Nakajima, M., Hagiwara, T., Sawaguchi, T., Yano, S., 2006: Bacterial cellulose/ silica hybrid fabricated by mimicking biocomposites. Journal of materials science 41(17): 5646-5656.

17. Maleki, H., Durães, L., Portugal, A., 2014: An overview on silica aerogels synthesis and different mechanical reinforcing strategies. Journal of Non-Crystalline Solids 385: 55-74.

18. Mulinari, D.R., Voorwald, H.J., Cioffi, M.O.H., da Silva, M.L.C., Luz, S.M., 2009: Preparation and properties of HDPE/sugarcane bagasse cellulose composites obtained for thermokinetic mixer. Carbohydrate Polymers 75(2): 317-321. 
19. Mulinari, D.R., Voorwald, H.J., Cioffi, M.O.H., Da Silva, M.L.C., da Cruz, T.G., Saron, C., 2009: Sugarcane bagasse cellulose/HDPE composites obtained by extrusion. Composites Science and Technology 69(2): 214-219.

20. Pothan, L.A., Bellman, C., Kailas, L., Thomas, S., 2002: Influence of chemical treatments on the electrokinetic properties of cellulose fibres. Journal of adhesion science and technology 16(2): 157-178.

21. Rodríguez-Robledo, M., González-Lozano, M., Ponce-Peña, P., Quintana Owen, P., Aguilar-González, M., Nieto-Castañeda, G., Bazán-Mora, E., López-Martínez, R., Ramírez-Galicia, G., Poisot, M., 2018: Cellulose-silica nanocomposites of high reinforcing content with fungi decay resistance by one-pot synthesis. Materials 11(4): 575.

22. Sibiya N.N., Mochane M.J., Motaung T.E., Linganiso L.Z., Hlangothi S.P., 2018: Morphology and properties of sugarcane bagasse cellulose- natural rubber composites. Wood Research 63: 821-832.

23. Sequeira, S., Evtuguin, D.V., Portugal, I., 2009: Preparation and properties of cellulose/ silica hybrid composites. Polymer composites 30(9): 1275-1282.

24. Terrett, O.M., Lyczakowski, J.J., Yu, L., Iuga, D., Franks, W.T., Brown, S.P., Dupree, R., Dupree, P., 2019: Molecular architecture of softwood revealed by solid-state NMR. Nature communications 10(1): 1-11.

25. Wei, C., Zeng, M., Xiong, X., Liu, H., Luo, K., Liu, T., 2015: Friction properties of sisal fiber/nanosilica reinforced phenol formaldehyde composites. Polymer Composites 36(3): 433-438.

26. Xie, K., Yu, Y., Shi, Y., 2009: Synthesis and characterization of cellulose/silica hybrid materials with chemical crosslinking. Carbohydrate Polymers 78(4): 799-805.

27. Zhao, J., Zhang, W., Zhang, X., Zhang, X., Lu, C. and Deng, Y., 2013. Extraction of cellulose nanofibrils from dry softwood pulp using high shear homogenization. Carbohydrate Polymers 97(2): 695-702.

\author{
Samson Masulubanye Mohomane \\ University of Zululand (Kwadlangezwa Campus) \\ Department of Chemistry \\ Private Bag Xiooi, Kwadlangezwa 3886 \\ Kwazulu Natal \\ South Africa \\ Setumo V. Motloung \\ Sefako Makgatho Health Sciences University \\ Department of Physics \\ P.O. Box 94, Medunsa 0204 \\ South Africa \\ Mandela University \\ Department of Physics \\ P. O. Box 77000 \\ Port Elizabeth 603 I \\ South Africa
}


Lehlohonolo Koao

University of The Free State (Qwaqwa Campus)

Department of Physics

Private Bag X I3 $_{3}$, Phuthaditjhaba 9866

South Africa

Tshwafo E. Motaung*

Sefako Makgatho Health Sciences University

Department of Chemistry

P.O. Box 94, Medunsa 0204

South Africa

University of South Africa

Department of Chemisry

Po Box 392, Pretoria OoO3

South Africa

*Corresponding author: motaungte@live.com 
